\title{
Erratum to: CT enterography of pediatric Crohn disease
}

\author{
Jonathan R. Dillman • Jeremy Adler •
}

Ellen M. Zimmermann • Peter J. Strouse

Published online: 15 December 2009

(C) Springer-Verlag 2009

\section{Erratum to: Pediatr Radiol}

DOI 10.1007/s00247-009-1465-5

The penultimate sentence of the last paragraph in the section "Pediatric CTE technique and radiation dose reduction" (page 98, right column) was rendered incorrectly due to an editing error. The sentence should have read:

"The effective dose of SBFT examination can be extremely variable, however, depending on the fluoroscope utilized, fluoroscopy time and number of radiographs acquired, and it can be greater than CTE."

The online version of the original article can be found at http://dx.doi. org/10.1007/s00247-009-1465-5.

J. R. Dillman $(\bowtie) \cdot$ P. J. Strouse

Department of Radiology, C.S. Mott Children's Hospital,

University of Michigan Health System,

Section of Pediatric Radiology, 1500 E. Medical Center Drive,

Ann Arbor, MI 48109, USA

e-mail: jonadill@med.umich.edu

\section{J. Adler}

Department of Pediatrics and Communicable Diseases,

Division of Pediatric Gastroenterology,

University of Michigan Health System,

Ann Arbor, MI, USA

\section{E. M. Zimmermann}

Department of Internal Medicine, Division of Gastroenterology, University of Michigan Health System,

Ann Arbor, MI, USA 